\title{
Comparison Of Eye Movements Between Patients With Schizophrenia And Healthy Patients During The Recognition Of Facial Emotions Test
}

\author{
M.D. GONZÁLEZ-MORIN C.A. ${ }^{1}$, M.D. JEREZ-GUADARRAMA D. ${ }^{2}$, Mr. CONTRERAS-CHAVEZ L.B. ${ }^{3}$, PhD. \\ MENDEZ-GARCIA M.O. ${ }^{4}$, M.S. ESPINOZA J. ${ }^{5}$, M.D. GUERRERO-HERRERA L.F. ${ }^{6}$ \\ Clínica Psiquiátrica "Dr. Everardo Neumann Peña"1, 5 \\ Universidad Autónoma de San Luis Potosí, 4 \\ Escuela de Medicina Universidad Cuauhtémoc San Luis Potosí ${ }^{1,2,5,6}$
}

\section{Objective}

To compare eye movements in patients with schizophrenia against healthy patients during facial recognition of emotions test.

\section{Background \& Aims}

Schizophrenia is a multifactorial disease that affects neurodevelopment and predisposes to neurodegeneration. It has an estimated prevalence of $1 \%$ of the population. Motor symptoms which correlate to neurological deterioration, are a measurable sign for diagnosis. In 2003 Williams et al. observed that patients with schizophrenia presented alterations in eye movements that correlate with the facial recognition pattern.

\section{Material and methods}

A case-control research was carried out, making use of a cross-sectional observational analysis with patients diagnosed with schizophrenia against healthy patients attending at the Psychiatric Clinic "Dr. Everardo Neumann Peña " at San Luis Potosí City.

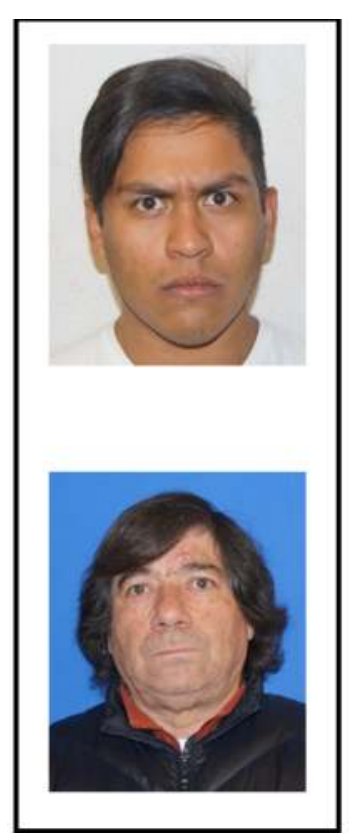

(a)

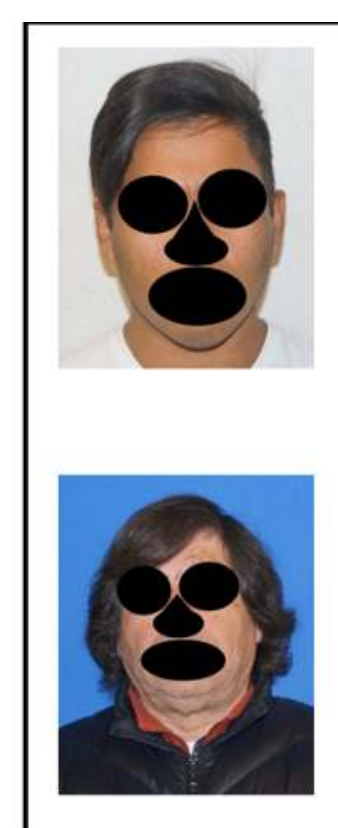

(b)

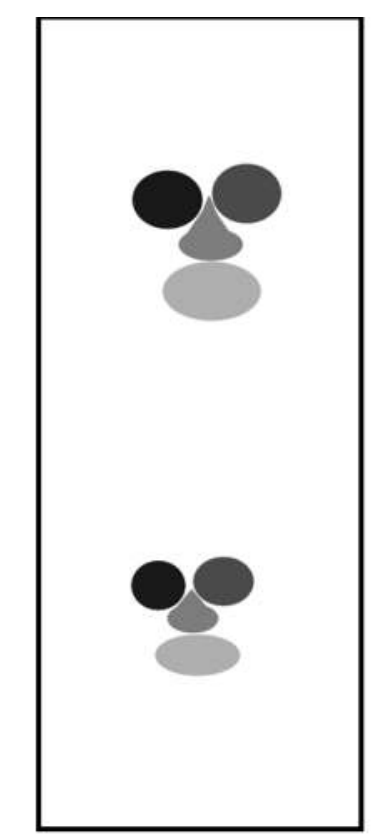

(c)

\section{Conclusions}

This study shows that there is a pattern in the eye movements of patients with schizophrenia during the recognition of facial emotions compared to healthy patients.

Consejo de Salubridad General. (2009). Diagnóstico y Tratamiento de la Esquizofrenia en el Primer y Segundo Nivel de Atención. GUÍA DE PRÁCTICA CLÍNICA, 2

O.M.S.: Trastornos mentales y del comportamiento, con glosario de definiciones, CDI-10 y notas diagnósticas. En: O.M.S.: GUIA DE BOLSILLO DE LA CLASIFICACIÓN CIE-10. Organización Mundial de la Salud. Editorial Médica 2000 May; 70-71.

Servicio Murciano de Salud. (2009). Guía Práctica Clínica Para el Tratamiento de la Esquizofrenia en Centros de Salud Mental. Salud Mental, 11-13.

Consejo Editorial de Educación Pública del Royal College of Psychiatrist. (2009). Esquizofrenia. Royal College of Psychiatrist, 1-3.

North SW, Shields CG. Schizophrenia: a review. Am Fam Physician. 2007 Jun 15:75(12):1821-9.

Marder SR, Galderisi S. La conceptuación de los sintomas negativos en la esquizofrenia. World Psychiatry (Ed Esp) 2017:15:14-24.

Results average of correct answers of 14 out of 40; the group of patients with schizophrenia (study group) had an average of 13 out of 40 correct answers. The average distance traveled and the average speed were higher in the study group, with a difference of 18,759 pixels for distance and 156.32 pixels/second for speed. The study group had a total upper average fixation in the nose, mouth and left eye compared to the control group.

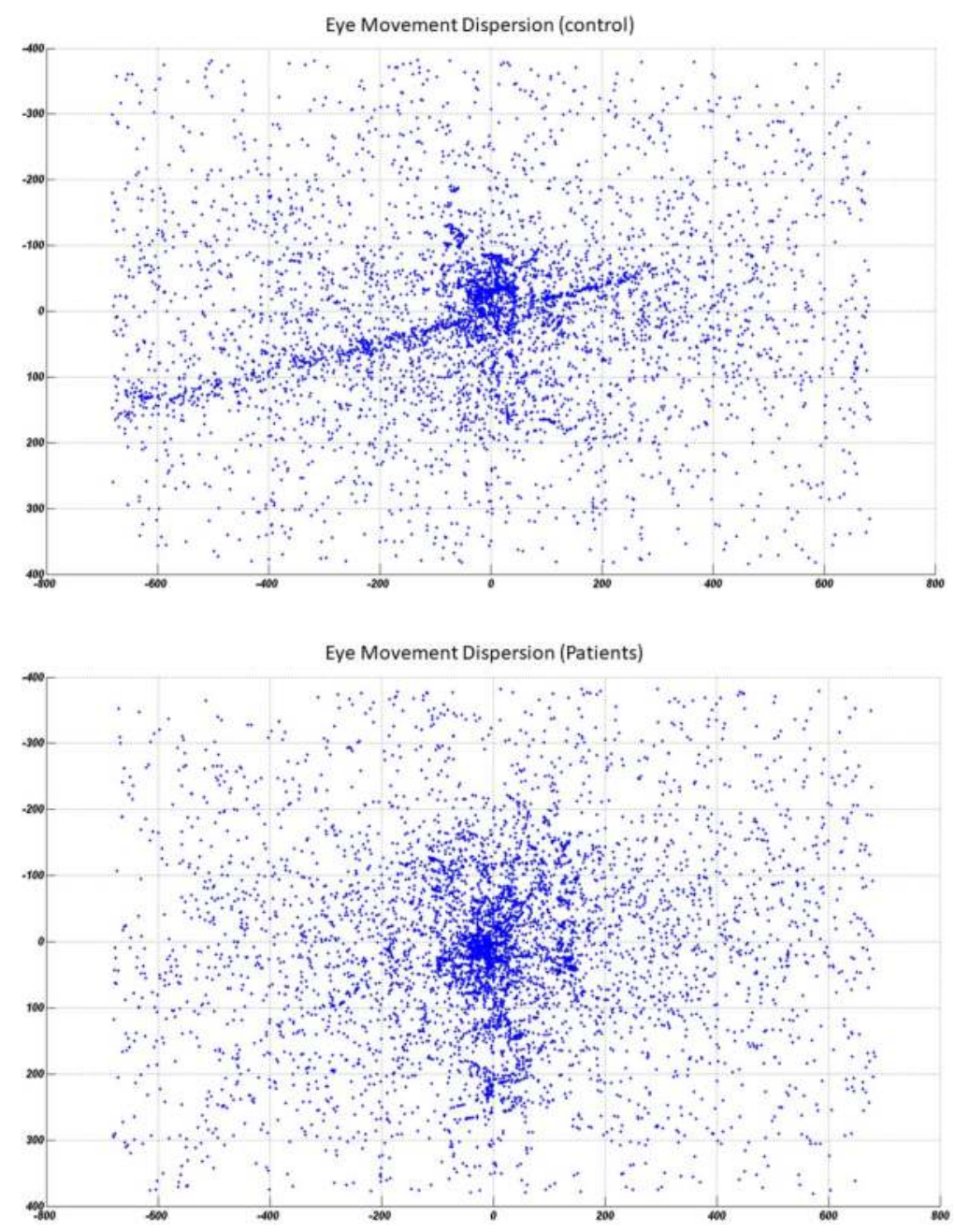

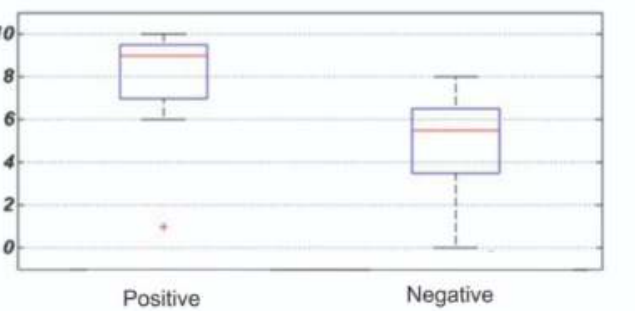

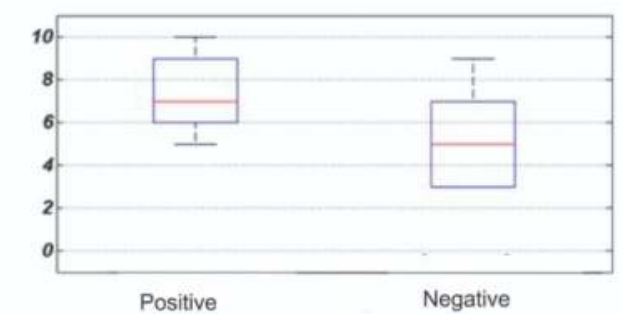

Control
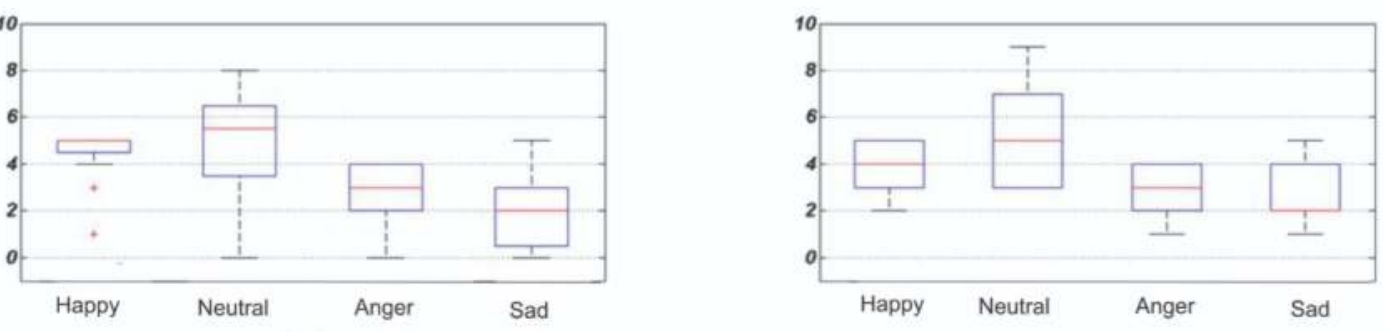